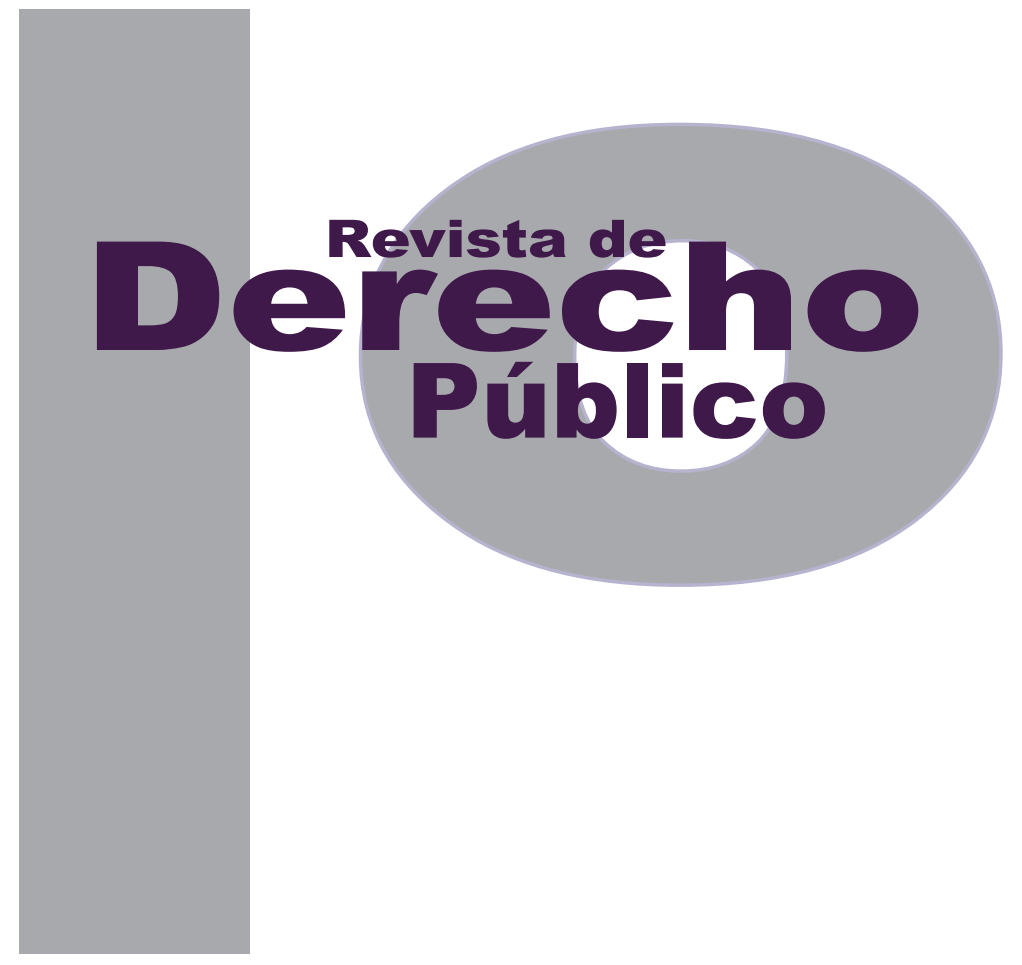

\title{
HACIA LA CONSTRUCCIÓN DEL CONTROL DE CONVENCIONALIDAD EN COLOMBIA
}

\author{
Paula Franco \\ Artículo de reflexión \\ DOI: http://dx.doi.org/10.15425/redepub.34.2015.25 \\ Universidad de los Andes \\ Facultad de Derecho \\ Revista de Derecho Público N. ${ }^{\circ} 34$ \\ Enero - Junio de 2015. ISSN 1909-7778
}




\section{Hacia la construcción del control de convencionalidad en Colombia Resumen}

El objetivo principal de este artículo es mostrar la caracterización que ha hecho la Corte Interamericana de Derechos Humanos (Corte IDH), a través de sus decisiones, sobre el concepto de control de convencionalidad y la aplicación que este ha tenido en Colombia. Específicamente, se pretende demostrar que el desarrollo de dicho concepto en las sentencias de la Corte Constitucional y del Consejo de Estado ha tenido un avance en cuanto a la integración normativa del corpus iuris interamericano con el ordenamiento jurídico interno. No obstante, nuestras cortes han sido tímidas en expresar la supremacía de este sobre todas las fuentes normativas domésticas, y por esto se han abstenido de realizar análisis propios del control de convencionalidad desligados del control de constitucionalidad, lo que ha impedido la construcción plena de este concepto en nuestro país.

Palabras clave: control de convencionalidad, control de constitucionalidad, bloque de constitucionalidad, responsabilidad del Estado, garantía de los derechos humanos, Corte IDH.

\section{Towards the construction of the conventionality control in Colombia}

Abstract

The main objective of this paper is to present the characterization that the Inter-American Court of Human Rights (IACHR) has made through its decisions of the concept of conventionality control and the implementation of this concept in CoIombia. In particular, we aim to demonstrate that the development of this concept in the decisions of the Constitutional Court and the State Council has had a breakthrough in terms of normative integration of the Inter- American corpus iuris with domestic law. However, our courts have been shy to express the supremacy of international standards on all national laws, and because of this, they have prevented the construction of a conventionality control of the laws that goes far beyond the traditional constitutional control.

Keywords: conventionality control, constitutional control, state responsibility, human rights, IACHR.

\section{Para uma construção do controle de convencionalidade na Colômbia Resumo}

O principal objetivo deste artigo é mostrar a caracterização que a Corte Interamericana de Direitos Humanos (Corte IDH) tem feito, através de suas decisões, sobre o conceito de controle de convencionalidade e a aplicação que este tem tido na Colômbia. Especificamente, se pretende demostrar que o desenvolvimento de dito conceito nas sentenças da Corte Constitucional e do Conselho de Estado tem tido um avanço sobre a integração normativa do corpus iuris interamericano com o ordenamento jurídico interno. Não obstante, nossas cortes têm sido tímidas em expressar a supremacia deste sobre todas as fontes normativas domésticas, e por isto se têm abstido de realizar análises próprias do controle de convencionalidade desligados do controle de constitucionalidade, o que tem impedido a construção plena deste conceito em nosso país.

Palavras-chave: controle de convencionalidade, controle de constitucionalidade, bloque de constitucionalidade, responsabilidade do Estado, garantia dos direitos humanos, Corte IDH. 


\title{
Hacia la construcción del control de convencionalidad en Colombia*
}

\author{
Paula Franco**
}

\section{SUMARIO}

Introducción - I. CARACTERIZACIÓN DEL CONTROL DE CONVENCIONALIDAD A PARTIR DEL DESARROLLO DE LA JURISPRUDENCIA DE LA CORTE IDH - A. Fundamento jurídico del control de convencionalidad - B. Control difuso de convencionalidad - C. Parámetros del control de convencionalidad: una aproximación a los componentes del corpus iuris interamericano - D. Efectos del control de convencionalidad - II. EVOLUCIÓN DE LA JURISPRUDENCIA COLOMBIANA EN MATERIA DE CONTROL DE CONVENCIONALIDAD - A. Bloque de constitucionalidad y el control de constitucionalidad - B. Decisiones de integración normativa con el corpus iuris interamericano - III. CONCLUSIONES - Referencias.

* Cómo citar este artículo: Franco, P. (Junio, 2015). Hacia la construcción del control de convencionalidad en Colombia. Revista de Derecho Público, 34. Universidad de los Andes (Colombia).

Este artículo corresponde exclusivamente a la opinión personal de la autora, y no compromete la responsabilidad de la Superintendencia Financiera de Colombia ni de ninguna otra entidad.

** Abogada de la Pontificia Universidad Javeriana. Candidata a magíster en Derecho Económico de la misma universidad. Abogada de la Superintendencia Financiera de Colombia. Correo: franco.paula@gmail.com 


\section{Introducción}

En el mundo actual hay una interacción constante entre el derecho interno y el derecho internacional, y particularmente en materia de protección de los derechos humanos el control difuso de convencionalidad constituye una de las expresiones más importantes de dicha interacción. Este control obliga a los Estados a coordinar las diferentes esferas del poder público y sus expresiones de poder, con miras a garantizar la efectividad de los derechos consagrados en los tratados internaciones; en esta construcción tiene un papel fundamental el juez como primera instancia de protección de los derechos humanos.

Así las cosas, este trabajo describirá el desarroIlo que ha tenido el concepto del control de convencionalidad en la jurisprudencia de la Corte Interamericana de Derechos Humanos (Corte IDH), específicamente el control difuso que deben realizar los jueces domésticos sobre las normas internas, y la aplicación que este ha tenido en las decisiones judiciales de nuestro país, para demostrar que el control de convencionalidad en Colombia ha sido utilizado como un fundamento de la atribución de responsabilidad del Estado o como parte del análisis del control de constitucionalidad de las normas, pero no bajo un contexto de control normativo autónomo, como lo ha planteado la Corte IDH, sino como una forma de integración de las normas internas y las internacionales con miras a garantizar la protección de los derechos humanos.

\section{CARACTERIZACIÓN DEL CONTROL DE CONVENCIONALIDAD A PARTIR DEL DESARROLLO DE LA JURISPRUDENCIA DE LA CORTE IDH}

\section{A. Fundamento jurídico del control de convencionalidad}

El origen del control de convencionalidad tanto en su modalidad concentrada, a cargo de la Corte IDH, como difusa, es el deber de garantía en cabeza de las diferentes ramas del poder público de los Estados partes contenido en el artículo 1.1 de la Convención Americana sobre Derechos Humanos (CADH). Precisamente, el hecho de que los Estados deban organizar todos los componentes de su aparato para que se proteja y asegure el libre y pleno ejercicio de los derechos humanos, implica que cualquier tipo de manifestación del poder público, sea una ley en sentido formal, o un acto de la administración, o una sentencia, debe velar por la prevalencia del contenido material del tratado y su efecto útil.

Desde el comienzo de su jurisprudencia, la Corte IDH ha establecido claramente este factor de imputación de responsabilidad amplio a las obligaciones en cabeza de los Estados. Así:

Todo menoscabo a los derechos humanos reconocidos en la Convención que pueda ser atribuido, según las reglas del derecho internacional, a la acción u omisión de cualquier autoridad pública, constituye un hecho imputable al Estado que compromete su responsabilidad en los términos previstos en la Convención (caso Velásquez Rodríguez vs. Honduras, párr. 164). 
También, esta obligación de garantía se nutre con la contenida en el artículo 2 de la CADH, donde se establece que los Estados se encuentran obligados a adoptar las medidas legislativas y de cualquier otro carácter para asegurar el libre y pleno ejercicio de los derechos humanos.

En este sentido, la doctrina ${ }^{1}$ ha dicho que esta interrelación necesaria entre los deberes generales de respetar y garantizar los derechos protegidos y de adecuar el ordenamiento jurídico interno para la efectiva protección de los derechos y libertades consagrados en la CADH, tiene origen en los principios generales de derecho internacional de pacta sunt servanda y de buena fe. Adicionalmente, existe una obligación general en cabeza del Estado de tomar todas las medidas de derecho interno para garantizar la protección eficaz (efecto útil) de los derechos consagrados, y como estas normas convencionales vinculan los Estados Partes -y no solamente sus Gobiernos-, también los Poderes Le-

1 Frente a esto, autores como Nogueira (2012) han considerado que "el control de convencionalidad que deben aplicar los jueces nacionales es una consecuencia necesaria de la aplicación de los principios de derecho internacional general y de derechos humanos, como una concreción de la regla de derecho consuetudinario que determina que el derecho interno no constituye una excusa para el incumplimiento de las obligaciones internacionales, que se encuentra positivada en la Convención de Viena sobre Derecho de los Tratados de 1969, en los artículos 26 y 31.1 que determinan el cumplimiento de buena fe de las obligaciones internacionales, como asimismo, el artículo 27 que determina que un Estado no puede oponer obstáculos de derecho interno al cumplimiento de las obligaciones internacionales. Ello implica necesariamente ajustar el derecho interno para hacerlo compatible con las obligaciones internacionales. La función de los órganos judiciales en este plano es hacer sus mejores esfuerzos para otorgar efecto útil a las normas internacionales, más aún cuando ellas constituyen derechos que emanan de la dignidad humana, los cuales deben ser efectivizados por el Estado-Juez a través de la adopción de las resoluciones jurisdiccionales conforme a las obligaciones generales establecidas por los artículos 1.1 y 2 de la $\mathrm{CADH}$, como asimismo a través de una interpretación favor persona y posibilitar el goce más amplio de los derechos de acuerdo con el artículo 29 de la misma Convención, evitando así incurrir en responsabilidad internacional por violación de derechos humanos a través de eventuales conductas omisivas". gislativo y Judicial, además del Ejecutivo, están obligados a tomar las providencias necesarias para dar eficacia a la Convención Americana en el plano del derecho interno. El incumplimiento de las obligaciones convencionales, como se sabe, compromete la responsabilidad internacional del Estado, por actos u omisiones, sea del Poder Ejecutivo, sea del Legislativo, sea del Judicial. En suma, las obligaciones internacionales de protección, que en su amplio alcance vinculan conjuntamente todos los poderes del Estado (Corte IDH, caso Caballero Delgado y Santana vs. Colombia, párrs. 8-10).

Esto se encuentra directamente relacionado con el llamado principio de integralidad de la responsabilidad del Estado, según el cual existe una responsabilidad unitaria del Estado por sus actos, de manera que el Estado Parte asume en el ámbito internacional unos deberes generales que cobijan a cada uno de los componentes de su estructura. En este sentido, se elimina la exoneración del Estado por la distribución de competencias, y todos los poderes públicos se obligan con la protección de los derechos humanos. El fundamento de esta forma de imputación data desde la Convención de Viena sobre el Derecho de los Tratados, cuyo artículo 29 dispone que: “Un tratado será obligatorio para cada una de las partes por lo que respecta a la totalidad de su territorio, salvo que una intención diferente se desprenda de él o conste de otro modo."

La consecuencia evidente de este principio es que si el legislador no adecua la norma interna a los parámetros internacionales, o el juez decide aplicar la norma y produce una sentencia 
que tampoco se ajusta a estos, se genera una responsabilidad internacional para el Estado, indistintamente del supuesto de hecho, y será declarada así por un tribunal internacional, en este caso la Corte IDH.

Al respecto la Corte IDH ha proferido fallos explícitos en los que se declara la responsabilidad de un Estado por los actos, incluso legislativos, u omisiones de cualquiera de sus poderes, y ha condenado al Estado a realizar unas reparaciones, que comprenden la adecuación de sus normas a los parámetros internacionales que ella misma ha fijado de acuerdo con su interpretación autorizada de la CADH.

Por ejemplo, en el caso "La Última Tentación de Cristo vs. Chile", la Corte fue enfática en afirmar que:

La responsabilidad internacional del Estado puede generarse por actos $\mathrm{u}$ omisiones de cualquier poder u órgano de éste, independientemente de su jerarquía, que violen la Convención Americana. Es decir, todo acto u omisión, imputable al Estado, en violación de las normas del Derecho Internacional de los Derechos Humanos, compromete la responsabilidad internacional del Estado. En el presente caso ésta se generó en virtud de que el artículo 19.12 de la Constitución establece la censura previa en la producción cinematográfica y, por lo tanto, determina los actos de los Poderes Ejecutivo, Legislativo y Judicial (párr. 72).

En el marco de los procesos contenciosos se ha alcanzado un relativo consenso acerca de que una de las funciones esenciales de la Corte IDH es realizar el control de convencionalidad con- centrado de las normas internas. Así no haya una norma expresa en la CADH sobre este tema específico, lo cierto es que se infiere del artículo 62.3 que la Corte IDH tiene competencia para conocer cualquier caso relativo a la interpretación y aplicación de las disposiciones del tratado.

En este sentido, la Corte IDH ha reiterado que "según el derecho internacional las obligaciones que éste impone deben ser cumplidas de buena fe y no puede invocarse para su incumplimiento el derecho interno". ${ }^{2}$ Esta regla ha sido codificada en el artículo 27 de la Convención de Viena sobre el Derecho de los Tratados de 1969.

Por otra parte, esta función del control de convencionalidad de la Corte IDH no se limita a los casos contenciosos, sino que incluye su función consultiva, ya que el artículo 64.2 de la CADH le otorga la facultad de emitir opiniones sobre la compatibilidad de las leyes internas a la luz del canon interamericano. Esto significa que la competencia no se circunscribe a realizar un examen de convencionalidad en sentido concreto, a la luz de un caso, sino también de forma abstracta, analizando únicamente la cuestión jurídica que se le plantea sin una referencia particular.

Una cuestión interesante es que esa facultad de realizar un control de convencionalidad se ha extendido a la Comisión Interamericana de Derechos Humanos ( $\mathrm{CIDH}$ ), quien también puede pronunciarse sobre el contenido material de

$2 \quad$ Al respecto, se puede ver, entre otros: Corte IDH. Opinión Consultiva OC-14/94 del 9 de diciembre de 1994. Responsabilidad Internacional por Expedición y Aplicación de Leyes Violatorias de la Convención (arts. 1 y 2 Convención Americana sobre Derechos Humanos), Serie A n. ${ }^{\circ} 14$, párr. 35. 
una norma jurídica adoptada en el orden interno. Al respecto, la Corte IDH afirmó en la opinión consultiva OC-13/93:

Lo que la Comisión debe verificar, en un caso concreto, es si lo dispuesto por la norma contradice la Convención y no si contradice el ordenamiento jurídico interno del Estado. La atribución otorgada a la Comisión para "formular recomendaciones (...) a los gobiernos de los Estados Miembros para que adopten medidas progresivas en favor de los derechos humanos dentro del marco de sus leyes internas y sus preceptos constitucionales" (art. 41.b) (destacado de la Corte) o el compromiso de los Estados de adoptar las medidas legislativas necesarias para hacer efectivos los derechos y libertades garantizados por la Convención "con arreglo a sus procedimientos constitucionales" (art. 2) (destacado de la Corte) no le dan a la Comisión facultad para calificar el cumplimiento por el Estado de los preceptos constitucionales en la elaboración de las normas internas (párr. 29).

Además, la Corte ha definido lo que significa la adecuación de las normas de derecho interno a los estándares internacionales de protección de derechos humanos, en dos esferas: i) la supresión de las normas y prácticas de cualquier naturaleza que entrañen violación a las garantías previstas en la Convención, y ii) la expedición de normas y el desarrollo de prácticas conducentes a la efectiva observancia de dichas garantías. ${ }^{3}$ Es necesario reafirmar que la obligación de la primera vertiente solo se satisface cuando efec-

3

Ver, entre otras, las siguientes decisiones de la Corte IDH: caso Ximenes Lopes vs. Brazil (2006, párr. 83); caso Gómez Palomino (2005, párr. 91); caso de la Masacre de Mapiripán vs. Colombia (2005, párr.109). tivamente se realiza la reforma de la norma que no se encuentra convencional. ${ }^{4}$

Nótese que en la primera esfera mencionada anteriormente se encuentra la primera diferencia marcada entre el control de constitucionalidad de Colombia y el control de convencionalidad, ya que el primero excluye el análisis de las normas de naturaleza constitucional, así en el estudio de las normas de otra naturaleza y jerarquía se incluyan parámetros internacionales como referente, dado el desarrollo de la figura del bloque de constitucionalidad que ha adoptado la jurisprudencia de la Corte Constitucional colombiana; en todo caso, es una expresión del principio de legalidad determinar si la norma fue expedida según la escala de fuentes normativas internas, por lo cual, sin negar que es un análisis tanto formal como material de las normas, sigue siendo un contraste con un referente doméstico.

En contraste, el control de convencionalidad implica una especie de supraconstitucionalidad en el que no basta con el análisis de las fuentes internas, sino que prima el estándar interamericano, cuyo pilar es la dignidad humana, y se vuelve un análisis puramente material del contenido de la norma, que no requiere de ninguna figura que integre las obligaciones internacionales al ordenamiento interno, por ejemplo, a través de la figura del bloque.

4 Ver, entre otras, las siguientes decisiones de la Corte IDH: caso Raxcacó Reyes vs. Guatemala (2005, párr. 87); caso Comunidad indígena Yakye Axa vs. Paraguay (2005. Fondo, Reparaciones y Costas, Serie C n. ${ }^{\circ}$ 125, párr. 100); caso Caesar vs. Trinidad y Tobago (2005. Fondo, Reparaciones y Costas, Serie $\mathrm{C} n .^{\circ} 123$, párrs. 91 y 93); y caso Almonacid Arellano y otros vs. Chile (2006, párr. 118). 
Esta visión del control de convencionalidad diferenciado del de constitucionalidad es congruente con el principio de subsidiariedad de las instancias internacionales frente a las nacionales, ya que si bien estas pueden analizar una norma a la luz de su ordenamiento interno, que, se insiste, pueden incluir normas de origen internacional como referente, lo cierto es que no siempre alcanzan a cubrir la totalidad del examen sobre el cumplimiento de los parámetros internacionales, lo que normalmente produce un incumplimiento del Estado de sus obligaciones internacionales, y la subsecuente declaratoria de responsabilidad internacional en la instancia correspondiente.

Específicamente, los requisitos de admisibilidad de los casos contenciosos ante el Sistema Interamericano de Protección de los Derechos Humanos es una expresión de este principio de subsidiariedad, ya que los artículos 46.1 literal a) y 61.2 de la CADH exigen la interposición y agotamiento de los recursos internos para poder acudir a esta jurisdicción internacional, lo que significa que la instancia internacional busca evitar la inactividad o desvío del Estado Parte porque no existen o no operan de manera adecuada los recursos internos para la solución del acto $u$ omisión que constituye un hecho ilícito internacional.

Entonces, el control difuso de convencionalidad, en virtud del cual los jueces domésticos realizan un control de las normas internas contrastándolas con el parámetro de protección de derechos humanos del Sistema Interamericano, según se explicará más adelante en detalle, tiene gran importancia para cumplir con el principio de subsidiariedad o complementariedad de la instancia internacional, toda vez que constituye un mecanismo judicial de contraste entre la legislación interna y el canon internacional (Ledesma, 2010, pág. 7). Es decir, se genera un recurso de protección interno de los derechos humanos, previo a la Corte IDH, que implica para los jueces realizar un verdadero esfuerzo de coordinación entre el sistema internacional y el sistema nacional, en beneficio de la eficacia en la protección y garantía de los derechos.

Por esto, el sector de la doctrina ${ }^{5}$ que defiende un modelo de control de convencionalidad difuso en cabeza de jueces domésticos afirma que su gran virtud es que:

La protección internacional se configura como una protección complementaria que no sustituye a la nacional sino que ambas se presentan como parte de una compleja maquinaria de garantía de derechos en una sociedad abierta y global. Estas dos dimensiones (nacional e internacional) de la protección de los derechos humanos determinan los nuevos entendimientos entre el derecho constitucional e internacional que requieren necesariamente de una "rehabilitación" del Estado en el escenario mundial, así como del fortalecimiento de las instancias supranacionales (Del Toro, 2005).

5 Sobre este punto, autores como Ortiz (2005, pág. 294) señalan que: "La ventaja que presenta el sistema de transformación del tratado [TIDH] en ley, se finca en que las dificultades que se presentan en su aplicación interna se reducen; sin embargo se corre el riesgo de que al perder su identidad internacional, los jueces utilicen como criterios de interpretación los establecidos en el derecho interno y no los marcados por el derecho internacional, que resultan obligatorios en razón de las normas convencionales o consuetudinarias, sobre la materia" [cursivas añadidas]. 


\section{B. Control difuso de convencionalidad}

En el presente acápite se describirá la posición de la Corte IDH respecto de la obligación que tienen todos los jueces internos, sin importar su jerarquía, de realizar un control de convencionalidad sobre la normatividad que van a aplicar en sus casos. Hay que aclarar que no se pretende ser exhaustivo en la presentación de los casos, porque muchas veces son reiterativos de la jurisprudencia precedente, simplemente se mencionarán los que reflejan de manera más patente el estado del arte sobre el asunto.

El primero que se quiere reiterar en esta sección es el caso Almonacid Arrellano y otros vs. Chile, en donde la Corte reflexiona acerca del comportamiento del Poder Judicial chileno, que ha dejado de aplicar en varias oportunidades desde 1998 el Decreto Ley n. 2.191 cuestionado en el caso, lo cual es valorado positivamente por dicho órgano. Lo que resulta fundamental de esta consideración es que la Corte parece insinuar que no es suficiente con que los jueces internos cesen la aplicación de la norma cuestionada, es decir, apliquen una especie de excepción de inconvencionalidad en el caso concreto, sino que para evitar la violación del artículo 2 de la CADH es necesario suprimir la disposición, teniendo en cuenta que el criterio de los jueces internos puede modificarse con el tiempo, y, por tanto, existe un riesgo de que la disposición interna cuestionada sea aplicada en el futuro.

Estas consideraciones resultan congruentes con la responsabilidad objetiva del Estado, ya explicada, dado que la norma interna está vio- lando per se la CADH, por su existencia y posibilidad de aplicación. El punto es que también puede resultar una puerta abierta para afirmar que no se trata solamente de que los jueces domésticos, de cualquier jerarquía o especialidad, puedan dejar de aplicar la norma no convencional en un caso concreto, y por tanto que la función del artículo 2 sea "facilitar la función del Poder Judicial de tal forma que el aplicador de la ley tenga una opción clara de cómo resolver un caso particular" (Corte IDH, caso Almonacid Arellano vs. Chile, párr. 123), sino que incluso estos, sin discriminación, puedan declararla de alguna manera carente de efectos en abstracto y a futuro para evitar los riesgos que la Corte identificó en este caso (esto puede ser denominado de diferentes maneras en cada país: nula, inconvencional, inconstitucional, etc.).

También en este caso hace una consideración fundamental para todo el desarrollo del control de convencionalidad difuso, que vale la pena transcribir en su totalidad:

La Corte es consciente que los jueces y tribunales internos están sujetos al imperio de la ley y, por ello, están obligados a aplicar las disposiciones vigentes en el ordenamiento jurídico. Pero cuando un Estado ha ratificado un tratado internacional como la Convención Americana, sus jueces, como parte del aparato del Estado, también están sometidos a ella, lo que les obliga a velar porque los efectos de las disposiciones de la Convención no se vean mermadas por la aplicación de leyes contrarias a su objeto y fin, y que desde un inicio carecen de efectos jurídicos. En otras palabras, el Poder Judicial debe ejercer una especie de "control de con- 
vencionalidad" entre las normas jurídicas internas que aplican en los casos concretos y la Convención Americana sobre Derechos Humanos. En esta tarea, el Poder Judicial debe tener en cuenta no solamente el tratado, sino también la interpretación que del mismo ha hecho la Corte Interamericana, intérprete última de la Convención Americana (párr. 124).

De aquí se derivan cuatro consecuencias muy importantes: la primera es que efectivamente todos los jueces de alguna manera se encuentran sometidos a la CADH por hacer parte de la integralidad que representa el Estado para el derecho internacional, por lo cual, debe haber al menos un órgano competente en el Poder Judicial interno que pueda declarar la inconvencionalidad de una norma, y retirarla si es el caso del ordenamiento jurídico; la segunda es que la CADH como fuente normativa se ubica por encima, al menos, de las leyes internas, por lo que deben respetar su objeto y fin; la tercera es que queda abierto el interrogante, que ha suscitado debates en la doctrina, acerca de si se trata de una "especie" de control de convencionalidad según el cual se deben interpretar los derechos y libertades de la normatividad interna acorde con los tratados, tal como lo sostiene Castilla (2014) al señalar que el control de convencionalidad nunca ha sido una novedad sustantiva, pues lo único que en el fondo les estaba exigiendo a las autoridades nacionales era que cumplieran con sus obligaciones internacionalmente adquiridas, que aplicaran la Convención Americana sobre Derechos Humanos (CADH) y la jurisprudencia derivada de esta, o de un verdadero control de convencionalidad difuso según el cual el juez puede aplicar directamente el tratado y dejar de aplicar una norma interna expedida válidamente, e incluso constitucional, con el argumento de que no es convencional, según lo plantea Fajardo (s.f.) en el caso mexicano; la cuarta consecuencia es que el corpus iuris interamericano no se compone únicamente del texto de la CADH sino de las interpretaciones hechas por la Corte IDH, como se señalará más adelante.

Por otra parte, es pertinente mencionar el caso Radilla Pacheco vs. México (2009), toda vez que dentro de las medidas de satisfacción y garantías de no repetición se encuentran consideraciones muy interesantes de la Corte IDH acerca de la interpretación que deben hacer los jueces domésticos del artículo 13 de la Constitución Política mexicana, de forma coherente con los principios convencionales y constitucionales de debido proceso y acceso a la justicia, contenidos en el artículo 8.1 de la Convención Americana y las normas pertinentes de la Constitución mexicana.

Entonces, la Corte IDH en este caso hace patente la diferencia entre las normas convencionales y las constitucionales, enfatizando en que estas últimas dependen en su interpretación adecuada de las primeras, lo que de por sí significa un cambio en el sistema de fuentes normativas tradicional, porque la supremacía ya no sería de la Constitución sino que esta debe armonizarse con las disposiciones del canon interamericano. Además, reafirma que la aplicación de las normas, sin importar su jerarquía, o su interpretación constitucional, por ser prácticas jurisdiccionales y una manifestación del orden público 
estatal, se deben encontrar ajustadas al mismo fin que persigue el artículo 2 de la CADH, so pena que constituyan hecho ilícito internacional. Con este razonamiento, la Corte IDH concluye que no es necesario ordenar la modificación de dicho artículo constitucional, sino adecuar su interpretación al canon interamericano, una solución que pueden tomar los jueces domésticos también.

El caso hito sobre control de convencionalidad difuso fue el caso Trabajadores cesados del Congreso vs. Perú (2006), en el que la Corte IDH analiza la inactuación de los jueces frente a una serie de normas que contenían medidas de administración de personal en el Congreso, e impedían a las personas la impugnación respecto al procedimiento de evaluación y eventual cesación. Aquí la Corte consideró que:

Los órganos del Poder Judicial deben ejercer no sólo un control de constitucionalidad, sino también "de convencionalidad" ex officio entre las normas internas y la Convención Americana, evidentemente en el marco de sus respectivas competencias y de las regulaciones procesales correspondientes. Esta función no debe quedar limitada exclusivamente por las manifestaciones $\mathrm{o}$ actos de los accionantes en cada caso concreto, aunque tampoco implica que ese control deba ejercerse siempre, sin considerar otros presupuestos formales y materiales de admisibilidad y procedencia de ese tipo de acciones (párr. 128).

Este es un caso hito porque no solo se reiteran los argumentos que anteriormente había planteado la Corte IDH en relación con el control de convencionalidad abstracto que deben realizar los jueces domésticos, sino porque se reconoce que dicho control está limitado también por las normas procedimentales internas y la estructura orgánica del Poder Judicial de cada país, es decir, se está reconociendo la necesidad de que cada Estado decida sobre la aplicación concreta del control de convencionalidad y no solamente que este tenga una aplicación automática sin ninguna regulación previa sobre cómo va a funcionar el control de convencionalidad y quién va a poder ejercerlo.

Precisamente, en este caso la Corte IDH responde una preocupación que tenían algunos doctrinantes ${ }^{6}$ acerca de la puerta abierta y la inseguridad jurídica a la que puede conducir este control de convencionalidad limitando las potestades del juez a sus competencias y regulaciones procesales, que son normas de orden público que se encuentran circunscritas al ordenamiento interno (Castilla, 2011, pág. 610).

Frente a esto, resulta relevante que a partir de lo señalado en la sentencia Radilla Pacheco vs. México donde se retoman consideraciones del caso Trabajadores cesados del Congreso vs. Perú, se generó el expediente Varios 912/2010 resuelto por el pleno de la Corte Suprema de Justicia, en el que este órgano judicial interno

6 Sobre este punto, Verbic (2012) indicó que la Corte Suprema de Justicia de la Nación para el caso argentino era quien debía encargarse del "avance en el establecimiento de estándares claros, precisos y administrables que sirvan de guía a los jueces inferiores. Jueces que, ante la ausencia del poder político que tiene el máximo tribunal y ante la posibilidad de que sus decisiones vengan revocadas por la alzada, tenderán a evitar el ejercicio del control de convencionalidad en la medida que no esté bien determinado cómo y cuándo pueden llevarlo adelante". 
declara las obligaciones concretas del Poder Judicial, en tanto parte del Estado mexicano, respecto al control de convencionalidad (Fajardo, s.f., pág. 21).

De todas formas, de acuerdo con lo esbozado por la Corte IDH en sus decisiones, independientemente de cómo se regule el ejercicio práctico del control difuso de convencionalidad, sea a través de un control abstracto de convencionalidad a cargo del tribunal constitucional con efectos erga omnes, o de una excepción de inconvencionalidad que puedan declarar los jueces de las diferentes jerarquías, resulta claro que, como mínimo, todos los jueces deberán poder plantear en sus fallos una especie de duda de inconvencionalidad de las normas que van a aplicar a un determinado caso para que la decisión definitiva sobre la permanencia de la norma sea establecida por la instancia correspondiente, dado que tienen la obligación de hacer este análisis de oficio, independientemente del alcance que finalmente tenga su decisión en concreto.

Por otra parte, en el caso Trabajadores cesados del Congreso vs. Perú (2006) también se plantea la posibilidad de unos presupuestos formales y materiales de admisibilidad y procedencia de este tipo de acciones para evitar su uso indiscriminado. Sin embargo, esto genera muchas preguntas para los Estados, porque no resulta muy claro de dónde van a inferirse esos presupuestos; si los debe crear cada uno con el riesgo de que no respondan a los parámetros internacionales pretendidos por la Corte IDH para este tipo de control de convencionalidad, o si debe asumirse que son los mismos que para acudir ante el Sistema Interamericano de Protección de los Derechos Humanos, en cuyo caso terminaría siendo de imposible aplicación para los jueces domésticos, por requisitos tales como el agotamiento de las instancias internas. Nótese que, por ejemplo, si se determina que solamente el tribunal constitucional puede ejercer el control de convencionalidad con unos requisitos muy estrictos para realizar el análisis se podría mermar el efecto expansivo del control.

Otro interrogante derivado de estas consideraciones de la Corte IDH es si se trata de un control abstracto de las normas o si se requiere que medie un caso concreto, aun cuando el impulso procesal de este no se encontraría, en principio, en cabeza de la parte interesada, por ser de oficio.

Sobre esto, se observa que la Corte IDH ya le ha atribuido la competencia de resolver un caso concreto a cierto juez por vía del control, como en el caso Cabrera García y Motiel Flores vs. México, en el que estableció: "Corresponde a las autoridades judiciales, con base en el control de convencionalidad, disponer inmediatamente y de oficio el conocimiento de los hechos por el juez natural, es decir el fuero penal ordinario" (2010, párr. 225).

Adicionalmente, en este caso el Estado mexicano alegó una excepción preliminar llamada "de cuarta instancia" y "control de convencionalidad", según la cual los jueces domésticos ya habían realizado un control de convencionalidad y, por tanto, la Corte IDH no podía revisar el asunto, 
dada la naturaleza complementaria que tiene la instancia internacional frente al derecho interno. Sin embargo, la Corte reiteró su posición acerca de que le corresponde a esta analizar el cumplimiento de los compromisos internacionales asumidos por el Estado, y esto incluye el análisis de las actuaciones judiciales a la luz del corpus iuris interamericano, como órgano que vela por la protección de los derechos humanos en el sistema, sin que esto implique valorar las pruebas y emitir una sentencia que eventualmente pudiera tener por efecto confirmar, modificar o revocar el veredicto nacional. Es decir, hay un control concentrado también para verificar la corrección de fondo de ese control de convencionalidad, sin que así vuelva una nueva instancia ni se trate de una excepción preliminar, sino una decisión de fondo sobre el asunto.

\section{Parámetros del control de convencionalidad: una aproximación a los componentes del corpus iuris interamericano}

Existe cierta claridad acerca de cuáles son los instrumentos internacionales que componen el corpus iuris interamericano, ya que los Estados han ratificado otros tratados diferentes a la CADH que contemplan la competencia de la Corte IDH para resolver controversias derivadas de sus disposiciones, y además la propia Corte ha ido ampliando este marco de instrumentos internacionales para la protección de los derechos.

Así, al referirse a un "control de convencionalidad" la Corte IDH ha tenido a la vista la aplicabilidad y aplicación de la Convención Americana sobre Derechos Humanos (Pacto de San José). Sin embargo, la misma función se despliega, por idénticas razones, en lo que toca a otros instrumentos de igual naturaleza, integrantes del corpus iuris convencional de los derechos humanos de los que es parte el Estado: Protocolo de San Salvador, Protocolo relativo a la Abolición de la Pena de Muerte, Convención para Prevenir y Sancionar la Tortura, Convención de Belém do Pará para la Erradicación de la Violencia contra la Mujer, Convención sobre Desaparición Forzada. A continuación se hará una breve mención sobre cada uno de estos instrumentos.

El primero es el Protocolo de San Salvador, cuyo artículo 19 numeral 6 dispone la competencia contenciosa de la Corte IDH para los casos de violaciones de los derechos establecidos en el párrafo a) del artículo 8 y en el artículo 13 de dicho instrumento.

Lo anterior no ha significado que de forma indirecta pueda vincular el contenido de este instrumento para integrar otros del Sistema Interamericano de Protección de los Derechos Humanos comprometidos en un caso concreto. Esto se ha presentado en algunos casos en los que el derecho a la vida o a la integridad personal se debe entender en conjunto con algunos derechos económicos, sociales y culturales (DEsc), tales como la salud y la educación. Un ejemplo de esto es el caso Ximenes Lopes vs. Brasil, en donde se protegió el derecho a la salud mental a través del concepto de vida digna y del derecho a la integridad, por lo que la muerte del señor Ximenes Lopes en una casa de reposo resultó siendo una fuente de responsabilidad internacional del 
Estado por el incumplimiento de los artículos 4 y 5 de la CADH; existen otros casos en los que ha sucedido esta integración entre la CADH y los DESC consagrados en el Protocolo de San Salvador. ${ }^{7}$

El segundo es el Protocolo relativo a la Abolición de la Pena de Muerte, que se integra a través del artículo 4 (derecho a la vida y restricción de la aplicación de la pena de muerte) de la $\mathrm{CADH}^{8}{ }^{8}$ y que tuvo su origen en la Opinión Consultiva OC-3/83 del 8 de septiembre de 1983 "Restricciones a la pena de muerte (arts. 4.2 y 4.4 Convención Americana sobre Derechos Humanos".

El tercero es la Convención Interamericana para Prevenir y Sancionar la Tortura (CIPST), cuyo artículo 8 establece que un caso sobre tortura podrá ser sometido a instancias internacionales cuya competencia haya sido aceptada por el Estado responsable, luego de que se hayan agotado los recursos internos.

Al respecto, la Corte IDH se ha pronunciado sobre su competencia para conocer presuntas violaciones a este tratado en casos como "Panel blanca" (Paniagua Morales y otros) vs. Guatemala y Niños de la calle (Villagrán Morales y otros) vs. Guatemala. En estos casos la Corte IDH estableció que se habían vulnerado los artículos 1,6 y 8 de la CIPST.

7 Ver, entre otros casos de la Corte IDH: Hermanos Gómez Paquiyauri vs. Perú (2004); Lori Berenson Mejía vs. Perú (2004); Ximenes Lopes vs. Brasil (2005)

8 Ver, entre otros, Corte IDH: caso Villagrán Morales y otros (caso de los "Niños de la calle"), 1999, párr. 144; caso Neira Alegría y otros (1995, párr. 74).
El cuarto es la Convención interamericana para prevenir, sancionar y erradicar la violencia contra la mujer, también llamada Convención de Belem do Pará. Específicamente sobre este instrumento, la Corte IDH ejerce competencia contenciosa respecto del artículo 7. Pese a esto, la Corte IDH ha utilizado artículos de esta Convención para la interpretación de ella misma y de otros instrumentos interamericanos en ejercicio de su competencia en casos contenciosos. También, es relevante que el artículo 7, h), de este tratado, contiene la obligación de adecuar la legislación interna a los estándares de derecho internacional, previendo así el control de convencionalidad.

El quinto es la Convención Interamericana sobre Desaparición Forzada de Personas (CIDFP), cuyo artículo XIII establece que el trámite de las peticiones o comunicaciones sobre desaparición forzada estará sujeto a los procedimientos establecidos en la $\mathrm{CADH}$, y en los estatutos y reglamentos de la $\mathrm{CIDH}$ y de la Corte IDH.

Así, en casos como el de Trujillo Oroza vs. Bolivia y en la sentencia de fondo del caso Gómez Palomino vs. Perú, se ha declarado la inconvencionalidad de las omisiones absolutas y relativas en la tipificación del delito de desaparición forzada por parte de los dos ordenamientos, respectivamente. La omisión relativa se debió, particularmente, a que la tipificación "no contiene todas las formas de participación delictiva que se incluyen en el artículo II de la Convención Interamericana sobre Desaparición Forzada de Personas, resultando así incompleta" (caso Gómez Palomino vs. Perú, párr. 102). 
También ha habido algunas aproximaciones por parte de los jueces domésticos en la aplicación de este instrumento; por ejemplo, en el caso Torres Millacura vs. Argentina, la Corte Suprema de Justicia de la Nación ordenó que el proceso penal para sancionar la desaparición forzada de Torres Millacura se realizara conforme a la CIDFP, a pesar de la falta de tipificación del delito en el Código Penal argentino (párr. 127).

Un asunto sobre el cual vale la pena reflexionar es si el juez nacional, como componente del todo que constituye el Estado para el derecho internacional, puede incluir dentro de su parámetro de convencionalidad aquellos instrumentos que no le otorgan competencia contenciosa a la Corte IDH, pero que han sido ratificados por el Estado Parte al que pertenece, o incluirlos así el Estado Parte no haya reconocido la competencia contenciosa de la Corte IDH. A este interrogante no hay una única respuesta, porque, en últimas, dependerá de la estructuración del funcionamiento del control de convencionalidad que se determine en el derecho interno, como se mencionó en el apartado anterior. Sin embargo, no resulta improbable que efectivamente la competencia del juez doméstico sea mayor a la del órgano internacional, porque, precisamente, la instancia internacional es subsidiaria o complementaria a los mecanismos internos del Estado. Entonces, entre más instrumentos sean contemplados por el juez doméstico para realizar su control de convencionalidad difuso, más estándares internacionales mínimos está evaluando el Estado, luego, teóricamente, está siendo más diligente en el cumplimiento de sus obligaciones internacionales.
Un aspecto que apoya el punto anterior es que la misma Corte IDH ha tratado de ejercer el control de convencionalidad concentrado de manera más flexible, y a veces parte de tratados sobre los que no tiene competencia contenciosa, por supuesto sin poder hacer un control directo sobre ellos, pero sí una interpretación de la CADH que permita un acercamiento indirecto a estos, precisamente buscando una protección más efectiva y amplia de los derechos humanos.

Por ejemplo, se ha vinculado el contenido del Protocolo de San Salvador, cuyo artículo 19 numeral 6 solamente dispone la competencia contenciosa de la Corte IDH para los casos de violaciones de los derechos establecidos en el párrafo a) del artículo 8 y en el artículo 13 de dicho instrumento, para casos de violaciones del derecho a la vida o a la integridad personal relacionados con derechos económicos, sociales y culturales, ${ }^{9}$ como en el caso Ximenes Lopes vs. Brasil, en donde se protegió el derecho a la salud mental a través del concepto de vida digna y del derecho a la integridad.

También, el Protocolo relativo a la Abolición de la Pena de Muerte, que tuvo origen en la Opinión Consultiva OC-3/83, se ha integrado a través del artículo 4 (derecho a la vida y restricción de la aplicación de la pena de muerte) de la $\mathrm{CADH}^{10}$

9 Ver, entre otras, las siguientes decisiones de la Corte IDH: caso de los Hermanos Gómez Paquiyauri vs. Perú (2004); caso Lori Berenson Mejía vs. Perú (2004); Caso Ximenes Lopes vs. Brasil (2005).

10 Ver, entre otros casos de la Corte IDH: Villagrán Morales y otros (caso de los "Niños de la calle"), (1999, párr. 144); Neira Alegría y otros (1995, párr. 74). 
Además, la Convención Interamericana para Prevenir y Sancionar la Tortura, que en su artículo 8 establece que un caso sobre tortura podrá ser sometido a instancias internacionales cuya competencia haya sido aceptada por el Estado responsable luego de que se hayan agotado los recursos internos, ha llevado a la Corte IDH a avocar conocimiento en casos como "Panel blanca" (Paniagua Morales y otros) vs. Guatemala y Niños de la calle (Villagrán Morales y otros) vs. Guatemala, declarando vulnerados sus artículos 1,6 y $8 .{ }^{11}$

Así mismo, frente a la Convención Interamericana para prevenir, sancionar y erradicar la violencia contra la mujer, la Corte IDH ejerce competencia contenciosa sobre el artículo 7. Pese a esto, ha utilizado artículos de esta Convención para la interpretación de ella misma y de otros instrumentos interamericanos en ejercicio de su competencia en casos contenciosos. ${ }^{12}$ También, es pertinente señalar que el artículo $7, \mathrm{~h}$ ), de este tratado, contiene la obligación de adecuar la legislación interna a los estándares de derecho internacional, previendo así el control de convencionalidad.

También, la Corte IDH ha concluido que su competencia consultiva, de carácter puramente jurídico-abstracto, puede ejercerse, en general, sobre toda disposición, concerniente a la protección de los derechos humanos, de cualquier

11 Sobre este punto, ver también el caso Heliodoro Portugal vs. Panamá (2008, párrs. 210-216).

12 Ver, entre otras, sus decisiones en los siguientes casos: González y otras ("Campo Algodonero") vs. México (2009); Penal Miguel Castro Castro vs. Perú (2006); Perozo y otros vs. Venezuela (2009). tratado internacional aplicable en los Estados americanos, con independencia de que sea bilateral o multilateral, de cuál sea su objeto principal o de que sean o puedan ser partes del mismo Estados ajenos al sistema interamericano (Opinión Consultiva OC-1/82, 1982).

Por otra parte, se ha debatido en la doctrina si la jurisprudencia de la Corte IDH es vinculante para los Estados, y en qué medida. Por ejemplo, Gómez Robledo (2000, pág. 45) considera que las opiniones consultivas carecen de fuerza obligatoria, mientras que Rodríguez (1998, pág. 485) encuentra que aunque las opiniones consultivas no son ejecutivas, no carecen de vinculación, particularmente las que se refieren a casos concretos en los que la Corte ha determinado la incompatibilidad de leyes internas con la Convención (citados por Mondragón, 2010).

Así las cosas, siguiendo a Hitters (2008, pág. 145), lo primero que debe aclararse es que para efectos de este trabajo, la jurisprudencia de la Corte IDH se entiende que incluye: los fallos o resoluciones proferidas en el marco de los casos contenciosos, las opiniones consultivas y las medidas provisionales.

Un sector de la doctrina opina que para los jueces domésticos únicamente es obligatorio observar la jurisprudencia de los casos contenciosos o las medidas provisionales en las que su Estado se encuentre involucrado, y el resto constituye un parámetro de orientación (Ayala, 2008, pág. 294). En contraste, hay quienes afirman que toda jurisprudencia de la Corte IDH es vinculante para los Estados, con fundamento en 
el deber de buena fe y en la figura de la "cosa interpretada" (Nogueira, 2011, pág. 33).

Esta última posición es la más cercana a la tendencia que ha seguido la jurisprudencia de la Corte IDH, porque, como se mencionó anteriormente, desde el caso Almonacid Arellano vs. Chile, y en otros posteriores, ha señalado que para el análisis de convencionalidad "el Poder Judicial debe tener en cuenta no solamente el tratado, sino también la interpretación que del mismo ha hecho la Corte Interamericana, intérprete última de la Convención" (Caso Almonacid Arellano vs. Chile, 2006, párr. 119).

Esto se explica porque siendo la Corte IDH el órgano supremo de interpretación y aplicación de los instrumentos del corpus iuris interamericano, a medida que resuelve casos concretos va generando reglas controlantes, de forma evolutiva. Estas no solamente conciernen a ese caso ni a ese Estado, sino que resultan siendo verdaderos estándares para la protección real y efectiva de los derechos humanos, que deberán observar los Estados so pena de comprometer su responsabilidad internacional. ${ }^{13}$

Además, la Corte IDH utiliza su jurisprudencia como estándares internacionales de protección de los derechos contenidos en el corpus iuris interamericano en repetidas ocasiones, para velar porque se mantenga el amparo alcanzado

13 Acerca de esta posición, Mc-Gregor (2011, pág. 917 y ss.) señaló que "pretender reducir la obligatoriedad de la jurisprudencia convencional sólo a los casos donde el Estado ha sido "parte material”, equivaldría a nulificar la esencia misma de la propia Convención Americana, cuyos compromisos asumieron los Estados nacionales al haberla suscrito y ratificado o adherido a la misma, y cuyo incumplimiento produce responsabilidad internacional". por este medio jurisdiccional. Un ejemplo claro de esto son las leyes de amnistía, sobre las que no solo reitera las violaciones a los derechos de las víctimas que estas suponen, sino también sus consideraciones precedentes a este respecto. Otro ejemplo son las disposiciones relativas a la pena de muerte. En el caso Boyce y otros vs. Barbados, la Corte IDH encontró que los jueces domésticos se habían limitado a evaluar si el artículo 2 de la Ley de Delitos contra la Persona era constitucional, cuando debieron evaluar su convencionalidad según la reiterada jurisprudencia acerca del alcance del artículo 4 de la CADH y la opinión consultiva OC- 3/83 sobre las restricciones a la pena de muerte.

Así, hay una distinción entre la "cosa interpretada" y la "cosa juzgada", según la cual la primera comprende todas esas reglas controlantes derivadas de las consideraciones expuestas en la jurisprudencia de la Corte IDH que son de contenido general, por ejemplo, cuando interpreta el alcance o elementos de un derecho de la CADH; mientras que la segunda es el efecto incontrovertible del fallo, que sí resulta afectando a un Estado en particular, por ejemplo, las reparaciones específicas a las que se le condene (Rodríguez, 1997, pág. 7).

Entonces, es indudable que una sentencia de la Corte es 'cosa juzgada', obligatoria para el Estado demandado en cuestión, pero también es 'cosa interpretada', válida erga omnes partes, en el sentido de que tiene implicaciones para todos los Estados Partes en la Convención en su deber de prevención. Sólo mediante un claro entendimiento de esos puntos fundamentales 
lograremos construir un orden público interamericano basado en la fiel observancia de los derechos humanos (Cançado, 2002, pág. 10).

En conclusión, la jurisprudencia de la Corte IDH hace parte del referente del análisis de convencionalidad que deben hacer los jueces domésticos, porque implica un desarrollo trascendente en materia de derechos humanos sobre los instrumentos que componen el corpus iuris. Esto no significa que los jueces internos no puedan realizar sus propias interpretaciones de las normas internacionales, sino que simplemente deben tener en cuenta ese mínimo impuesto por el órgano internacional, e identificar la aplicabilidad del precedente para el caso concreto, o motivar su separación de este sin perder de vista el objeto y fin de los instrumentos internacionales.

Ahora, en el caso de los países con un sistema de precedente judicial, puede construirse un estándar cada vez más alto de protección de los derechos humanos a nivel interno, toda vez que las diferentes decisiones de los jueces domésticos de la mayor jerarquía que hacen análisis de convencionalidad serán de obligatorio cumplimiento para todos los demás, generándose parámetros internos de protección de los derechos humanos que resuelvan de manera cada vez más efectiva los casos que se presenten en el Estado que involucren la protección de derechos humanos, evitando así llegar a la instancia internacional.

\section{Efectos del control de convencionalidad}

No existen muchas consideraciones acerca de los efectos que debe tener un fallo que determine la convencionalidad de una norma por parte de un juez interno. Sin embargo, se puede hacer una aproximación desde los efectos que se han dado en materia de control concentrado de convencionalidad.

Una primera anotación interesante es que el control de convencionalidad no se encuentra supeditado únicamente a normas expedidas por el Estado que no cumplen los parámetros internacionales en protección de derechos humanos, sino también a las omisiones legislativas que impiden que se logren esos parámetros. Un ejemplo de esto, mencionado en el acápite anterior, es el examen que realizó la Corte IDH sobre la ausencia de tipificación del delito de desaparición forzada en los ordenamientos internos.

Así, en el caso Heliodoro Portugal vs. Panamá, la Corte IDH determinó que esta omisión legislativa viola el artículo 2 de la CADH y el artículo III de la CIDFP, ya que impide el desarrollo efectivo de un proceso penal por la comisión de esos delitos, en detrimento de las víctimas. La conclusión de este caso fue la condena al Estado a que tipifique los delitos de desaparición forzada de personas y tortura, en un plazo razonable. Esta obligación únicamente se entiende cumplida cuando "el proyecto de ley se convierta en ley de la República y entre en vigor, lo cual debería efectuarse en un plazo razonable" (caso 
Heliodoro Portugal vs. Panamá, supervisión de cumplimiento de sentencia, párr. 36).

La orden de subsanar la omisión legislativa y los requisitos, para que se entienda plenamente cumplida la obligación, a mi entender es factible en el ámbito interno también. De hecho, la Corte Constitucional de Colombia no es ajena a este tipo de órdenes. El juez interno también podría recurrir, si ello es posible, a llenar el vacío por medio de la aplicación directa de la CADH, por ejemplo, si el derecho específico no se encuentra consagrado en la legislación interna, podría igual ampararse con una remisión directa al instrumento internacional, evitando que se consume el daño por el hecho ilícito internacional de la no adecuación de las normas internas (artícuIo $2 \mathrm{CADH}$ ).

Una segunda esfera de efectos es la que se deriva de la declaración de inconvencionalidad de una norma del ordenamiento interno. Es importante aclarar que los pronunciamientos que hace la Corte IDH solamente reflejan el incumplimiento de las obligaciones internacionales del Estado, y no tienen el efecto de retirar del ordenamiento jurídico interno una norma -dependiendo de cada país será anularla, declararla inexequible, etc.-, esto corresponde al Estado.

Lo que sí hace la Corte IDH es señalar unas medidas de reparación, según el artículo 63.1 de la CADH, por la violación del artículo 2 y 1.1 de la misma CADH, tales como la modificación, la reinterpretación, la derogación o de algún modo la carencia de efectos de las normas o prácticas que ocasionaron la violación. La implicación de esto último es que: 1), la norma tiene que dejarse de aplicar a futuro, en cualquier controversia, mientras se expide la modificación correspondiente o una nueva que la reemplace, o simplemente se retira del ordenamiento aquella que no es convencional, según los procedimientos internos de cada Estado y la orden concreta del fallo. Esta inaplicación es manifestación de un cierto control de convencionalidad por parte de los jueces internos sujetos a lo ya dispuesto por la Corte IDH sobre dicha norma; 2) si se trata de reinterpretar la norma, los operadores jurídicos tienen que adoptar la interpretación que se haya encontrado conforme al corpus iuris interamericano y abandonar la anterior, sea con efectos erga omnes o inter partes según su competencia.

Así, resulta complicado hacer la transferencia de estas medidas al control difuso de convencionalidad, porque en el orden interno cada Estado tiene definidas sus competencias dentro del Poder Judicial, y los efectos de un fallo de inconvencionalidad dependerá de quién profiera la decisión, sin que pueda un juez ordenar medidas fuera de su competencia. Por ejemplo, el juez constitucional en Colombia podría declarar inexequible la norma, dándole efectos erga omnes a esta decisión y retirándola así definitivamente del ordenamiento jurídico, o podría condicionarla para que su interpretación sea aquella convencional con los mismos efectos, pero un juez ordinario únicamente podría darle efectos inter partes a su decisión, e inaplicar la norma en el caso concreto o aplicarla con la interpretación convencional, haciendo uso de lo que hemos Ilamado excepción de inconvencionalidad. 
Vale la pena señalar que, de manera algo atípica, la Corte IDH ha determinado que las leyes de autoamnistía son inconvencionales per se desde su expedición, por lo que los efectos del fallo se remontan a casos anteriores a los analizados específicamente en el litigio que genera la discusión inicialmente en la instancia internacional, como en el caso Barrios Altos vs. Perú, donde determinó que "dada la naturaleza de la violación constituida por las leyes de amnistía n. ${ }^{\circ} 26479$ y n. ${ }^{\circ} 26492$, lo resuelto en la sentencia de fondo en el caso Barrios Altos tiene efectos generales". ${ }^{14}$ Existe alguna duda sobre si esto sería posible en el ámbito interno de los Estados, dado que si bien el deber de reparar las vulneraciones de los derechos humanos para las víctimas tiene mucho que ver con asuntos tales como la investigación de los delitos, los jueces tienen competencias demarcadas que les impiden dictar medidas de reparación hasta la retroactividad de una declaratoria de inconvencionalidad de una norma, incluso otro tipo de medidas.
14 Por ejemplo, en el caso La Cantuta vs. Perú (párr. 174) señaló: "Para efectos de la discusión planteada, es necesario precisar que la Corte consideró que en Perú dichas leyes de autoamnistía son ab initio incompatibles con la Convención; es decir, su promulgación misma "constituye per se una violación de la Convención" por ser "una ley manifiestamente contraria a las obligaciones asumidas por un Estado parte" en dicho tratado. Ese es el rationale de la declaratoria con efectos generales realizado por la Corte en el caso Barrios Altos. De ahí que su aplicación por parte de un órgano estatal en un caso concreto, mediante actos normativos posteriores o su aplicación por funcionarios estatales, constituya una violación de la Convención".

\section{EVOLUCIÓN DE LA JURISPRUDENCIA COLOMBIANA EN MATERIA DE CONTROL DE CONVENCIONALIDAD}

\section{A. Bloque de constitucionalidad y el control de constitucionalidad}

El bloque de constitucionalidad es una figura de integración normativa que ha servido, entre otros, para nutrir el contenido del texto constitucional con otras disposiciones que no se encuentran formalmente en este, pero que constituyen un referente para el control de constitucionalidad, en tanto se sitúan en el mismo nivel jerárquico que la Constitución Política.

Al respecto, resulta relevante la interpretación que ha desarrollado la Corte Constitucional del artículo 93 de la Constitución en punto a la incorporación de tratados de derechos humanos al bloque de constitucionalidad y su alcance frente al control constitucional:

El inciso primero del artículo 93 de la Carta permite incorporar ciertos derechos y principios al bloque de constitucionalidad, incluso cuando éstos no han sido reconocidos por el articulado constitucional, pero para ello se requiere que sean derechos no limitables en estados de excepción. Este artículo 93-1 adquiere entonces una verdadera eficacia cuando se trata de derechos o principios que no aparecen expresamente en el articulado constitucional, pero que se refieren a derechos intangibles incorporados en tratados ratificados por Colombia. Por su parte, el inciso segundo del artículo 93 superior tiene otra finalidad pues esa norma 
completa y dinamiza el contenido protegido de un derecho que ya está consagrado en la Carta, puesto que, conforme a ese inciso, tal derecho debe ser interpretado de conformidad con los tratados ratificados por Colombia" (CConst., T-1319/2001, R. Uprimny).

Así las cosas, son un parámetro del control de constitucionalidad de las normas jurídicas internas aquellas disposiciones de tratados internacionales de derechos humanos que no pueden limitarse en estados de excepción, toda vez que tienen rango constitucional, y aquellos que no cumplan dicha condición no integran el bloque de constitucional como referentes normativos directos sino como "como herramientas hermenéuticas para juzgar la legitimidad de la normatividad interna", como lo serían las decisiones de las instancias internacionales competentes respecto a los diferentes tratados (CConst, T-1319/2001, R. Uprimny).

En consecuencia, considero que el control de constitucionalidad de las normas ha subsumido el control de convencionalidad, integrándolas al texto constitucional con la figura del bloque de constitucionalidad, pero esto en el fondo implica un desconocimiento de la supraconstitucionalidad del corpus iuris interamericano como parámetro de control convencional.

Al respecto, resulta ilustrativo pensar en el siguiente caso:

Una norma subconstitucional nacional debe superar dos vallas: la del control de constitucionalidad, y la del control de convencionalidad. Si cae por alguna de ellas, resulta inaplicable.
Esto, como regla. Sin embargo, pueden darse situaciones especiales. Supóngase que una ley viole la Constitución nacional, pero coincida con el Pacto de San José. Tómese, siempre como conjetura, el caso del derecho de réplica, rectificación o respuesta, expresamente enunciado en el Pacto (Art. 14), pero hipotéticamente negado por una Constitución. ${ }^{15}$ Si se dictara allí una ley reglamentaria del mismo, ella resultaría inconstitucional, pero en cambio, sería convencional. Como aquella cláusula constitucional negatoria de un derecho de fuente convencional padecería de "inconvencionalidad", la ley reglamentaria del derecho, en el caso presunto que comentamos, concluiría válida, por la superioridad del Pacto sobre la Constitución, conforme a la doctrina del control de convencionalidad (Sagüés, 2010, pág. 117).

En este sentido, uno puede preguntarse: ¿si los derechos y deberes constitucionales deben ser interpretados de conformidad con los tratados de derechos humanos y la jurisprudencia de los órganos internacionales, entonces dichos instrumentos internacionales no se encuentran en una jerarquía normativa superior a la constitucional y no deben simplemente integrarse a esta? Opino que la respuesta es afirmativa, y en ello coincido con la posición de la Corte IDH sobre la obligación internacional del Estado, en cabeza de los jueces, de realizar un control más allá del puramente constitucional.

\footnotetext{
15 En Argentina, algunas constituciones provinciales han prohibido el ejercicio del derecho de réplica. Ver Sagüés (2008, pág. 149).
} 


\section{B. Decisiones de integración normativa con el corpus iuris interamericano}

Como se ha venido explicando, en Colombia no existe ningún pronunciamiento donde expresamente se realice un control de convencionalidad de las normas del ordenamiento interno teniendo como parámetro el corpus iuris interamericano, sino una integración con normas internacionales en aras de garantizar la protección de los derechos humanos.

Es así, como la Corte Constitucional y el Consejo de Estado se han pronunciado en varias oportunidades teniendo como fundamento disposiciones del corpus iuris interamericano, entre estas, la jurisprudencia de la Corte IDH. A continuación se presentarán algunos casos que se consideran de especial relevancia por mostrar la posición que tienen estas dos corporaciones frente a ciertas características del control de convencionalidad.

Un primer caso es el contenido en la sentencia C-187 de 2006 (C. I. Vargas), en la que se estudia la constitucionalidad de un proyecto de ley estatutaria referente a la reglamentación del artículo 30 C. P., que consagra el hábeas corpus. En este fallo se realizó un análisis acerca de la intangibilidad del derecho al hábeas corpus, partiendo del artículo 27.2 de la CADH, así como de lo dispuesto en el artículo $4^{\circ}$ de la Ley 137 de 1994 -Ley Estatutaria sobre Estados de Excepción-, donde se consagra que no podrán ser suspendidas las "garantías judiciales indispensables" para la protección de los derechos enunciados en cada uno de dichos artículos, dentro de los cuales la norma estatutaria incluye el hábeas corpus como uno de los derechos intangibles.

Además, recuerda lo afirmado en la Opinión Consultiva 08/87 sobre Habeas Corpus bajo suspensión de garantías, ${ }^{16}$ en cuanto a que hay una relación de necesidad entre el debido proceso del artículo 8 de la CADH y las garantías judiciales indispensables, en la medida en que respecto de estas garantías es preciso que se preserve de manera integral el debido proceso. ${ }^{17}$

Sin embargo, la Corte Constitucional afirmó, en esta oportunidad, que:

Los pronunciamientos adoptados por los órganos internacionales competentes para interpretar o aclarar el contenido, alcance o valor jurídico de una disposición contenida en una norma internacional de derechos humanos bien del sistema universal o bien del sistema interamericano, como doctrina o jurisprudencia internacional, por ser relevante constitucionalmente sirve a los órganos nacionales como criterio auxiliar de interpretación (C-187/2006, C. I. Vargas).

16 (Arts. 27.2, 25.1 y 7.6 Convención Americana sobre Derechos Humanos). Serie $A$ n. ${ }^{\circ} 8$.

17 Es interesante observar que hay varios pronunciamientos de la Corte Constitucional en los que se incorporan las opiniones consultivas de la Corte IDH para establecer el alcance de los derechos y calificarlos como intangibles. Ver, por ejemplo, la aplicación de la Opinión Consultiva 09 de octubre 6 de 1987 sobre garantías judiciales en estados de emergencia (arts. 27.2, 25 y 8 Convención Americana sobre Derechos Humanos) en las sentencias C-496 de 1994, M. P.: Alejandro Martínez Caballero; T-260 de 1999, M. P.: Eduardo Cifuentes Muñoz; C-200 de 2002, M. P.: Álvaro Tafur Galvis. También, la Opinión Consultiva 17 de agosto 28 de 2002 sobre condición jurídica y derechos humanos del niño, en la sentencia C-510 de 2003, M. P.: Manuel José Cepeda Espinosa. 
Esta posición claramente va contra el estándar que ha fijado la Corte IDH desde el caso Almonacid Arellano y otros vs. Chile, ya que, como intérprete autorizado del corpus iuris interamericano, todas las reglas controlantes que se derivan de las consideraciones de sus sentencias son obligatorias para los Estados parte. En consecuencia, no son simplemente un criterio auxiliar, que el juez puede elegir aplicar o no, sino que constituyen el desarrollo del contenido de los derechos y garantías consagrados en los instrumentos, por lo cual son inescindibles en la aplicación adecuada y convencional de estos.

En los últimos años, esta posición ha sido atenuada por la Corte Constitucional quien ha señalado que la jurisprudencia de la Corte IDH es un criterio relevante para fijar el parámetro de control de las normas que hacen parte del ordenamiento interno colombiano, ${ }^{18}$ pero aún no reconoce su aplicación directa en nuestro ordenamiento y sigue vinculándolo con el control de constitucionalidad al integrar dichos pronunciamientos al bloque de constitucionalidad. De hecho, cuando estudió las disposiciones sobre los tipos penales de injuria y calumnia señaló que las decisiones de la Corte IDH:

Constituye[n] un precedente significativo (...) esta decisión no puede ser trasplantada automáticamente al caso colombiano en ejercicio de un control de convencionalidad que no tenga en cuenta las particularidades del ordenamiento jurídico interno, especialmente la jurisprudencia constitucional y de la Corte Suprema

18 Ver, entre otras de sus sentencias, la C-936 de 2010, M. P.: Luis Ernesto Vargas Silva. de Justicia que han precisado notablemente el alcance de los elementos normativos de estos tipos penales (CCons., C-442/2011, H. A. Sierra Porto).

Por otra parte, considero que un caso hito de aplicación de parámetros interamericanos en nuestra jurisprudencia es el resuelto en la sentencia C-370 de 2006 (M. J. Cepeda y otros), con ocasión del análisis de constitucionalidad de varias normas contenidas en la Ley 975 de 2005, también Ilamada Ley de Justicia y Paz.

En este la Corte realiza un estudio amplio acerca de los derechos de las víctimas, contenidos en varios instrumentos internacionales no solo del sistema interamericano, sino en otros universalmente reconocidos, tales como el Conjunto de principios para la protección y la promoción de los derechos humanos mediante la lucha contra la impunidad, proclamados por la Comisión de Derechos Humanos de la onu en 1998.

Las consideraciones más relevantes de la sentencia se basan en una recopilación que hace la Corte Constitucional de pronunciamientos hechos por la Corte $\mathrm{IDH},{ }^{19}$ en los que se acogen fundamentos relativos a estándares sobre justicia, no repetición, verdad y reparación de las víctimas de los graves atentados contra el derecho internacional de los derechos humanos y el derecho internacional humanitario. La posición de la Corte Constitucional en esta sentencia es

19 Se mencionan expresamente los pronunciamientos de la Corte IDH en los siguientes casos: Godínez Cruz vs. Honduras (1989); Barrios Altos vs. Perú (2001); Bámaca Velásquez vs. Guatemala (2000); Myrna Mack Chang vs. Guatemala (2003); Hermanos Gómez Paquiyauri vs. Perú (2004); “La Masacre de Mapiripán” vs. Colombia (2005, párr. 223); Comunidad Moiwana vs. Suriname (2005). 
muy interesante porque logra hacer una especie de ponderación entre el interés del Estado de alcanzar la paz, y los parámetros internacionales y constitucionales sobre derechos de las víctimas, en el marco de un proceso que podría catalogarse como de justicia transicional, a pesar de continuar el conflicto armado interno.

En este pronunciamiento, al tratar el tema del reconocimiento de las víctimas, la Corte Constitucional vuelve a aplicar las reglas que ha establecido la Corte IDH, que las cataloga en un sentido amplio, y señala que los parientes, sin distinción, que puedan demostrar el daño, tienen derecho a un recurso efectivo para exigir la satisfacción de sus derechos a la verdad, a la justicia y a la reparación.

Concluye la Corte diciendo que:

Viola el derecho a la igualdad y los derechos de acceso a la administración de justicia, al debido proceso y a un recurso judicial efectivo las disposiciones de la Ley demandada [Ley 975 de 2005] que excluyen a los familiares que no tienen primer grado de consanguinidad con la víctima directa, de la posibilidad de que, a través de la demostración del daño real, concreto y específico sufrido con ocasión de las actividades delictivas de que trata la ley demandada, puedan ser reconocidos como víctimas para los efectos de la mencionada Ley. También viola tales derechos excluir a los familiares de las víctimas directas cuando éstas no hayan muerto o desaparecido. Tales exclusiones son constitucionalmente inadmisibles, lo cual no dista para que el legislador alivie la carga probatoria de ciertos familiares de víctimas directas estableciendo presunciones como lo hizo en los incisos 2 y 5 del artículo 5 de la ley acusada (CConst., C-370/06, M. J. Cepeda et al., fundamento jurídico $n .^{\circ}$ 6.2.4.2.15).

Podría afirmarse que la conclusión a la que llega la Corte Constitucional respecto a la exequibilidad condicionada de los apartes de dicha norma, ${ }^{20}$ es también una interpretación convencional de estos, ya que se refiere expresamente al recurso judicial efectivo consagrado por la CADH en el artículo 8, en concordancia con el artículo 25. Sin embargo, el fallo se limita a darle una connotación constitucional, al encontrar que este derecho hace parte del bloque de constitucionalidad, y tiene su reflejo en alguna disposición del texto constitucional, al igual que el resto de derechos de las víctimas.

Por su parte, el Consejo de Estado ha hecho explícito en sus análisis el control de convencionalidad pero no respecto a normas jurídicas, sino frente a casos concretos relativos a la responsabilidad atribuible al Estado en el marco de acciones de reparación directa.

Dicha corporación ha circunscrito este control a aquellos casos en los que considera que se presentaron graves violaciones a los derechos humanos, particularmente respecto a conductas omisivas del Estado en situaciones generalmente relacionadas con acciones de grupos al margen de la ley. ${ }^{21}$ Es interesante observar que

20 Incisos segundo y quinto del artículo 50; artículo 47; numeral 49.1 y 49.3 del artículo 48 de la Ley 975 de 2005

21 Ver, entre otras, las siguientes decisiones de la Sección Tercera del Consejo de Estado: H. A. Rincón, sentencia del 23 de febrero de 2012, rad. n. ${ }^{\circ}$ 54001-23-31-000-1999-00385-01(23027); J. O. Santofimio, auto del 24 de septiembre de 2012, expte. 50001-23-31-000-2011- 
en los casos en los que ha actuado como juez interamericano a nivel nacional (ver nota 21), señala que se determinará si el Estado vulneró normas internaciones de derechos humanos y desconoció su posición de garante, utilizando como fundamento el artículo 1.1. de la CADH y otros instrumentos, tales como la Convención sobre Desaparición Forzada de Personas ${ }^{22}$ y la Convención de Belém do Pará. ${ }^{23}$ En este sentido, la interpretación del corpus iuris interamericano como parámetro del control de convencionalidad tiene un sentido amplio para esta corporación, acorde con la tendencia ya analizada de la Corte IDH.

Adicionalmente, reconoce que "este control no solo se agota en la verificación del cumplimiento de normas convencionales, sino que también se extiende a la verificación de la interpretación que de ellas se ha llevado a cabo por la Corte Interamericana de Derechos Humanos" (CE, 21 nov. 2013, E. Gil Botero). Nótese que esta posición difiere de la establecida por la Corte Constitucional en algunas de sus sentencias.

00586-01 (44050); J. O. Santofimio, sentencia del 17 de octubre de

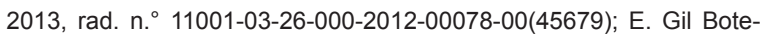
ro, sentencia del 21 de noviembre de 2013, rad. No. 05001-23-31000-1998-02368-01(29764); R. Pazos Guerrero, sentencia del 06 de diciembre de 2013, rad. n. $05001-23-31-000-2000-03380-01$ (26669); H. A. Rincón, sentencia del 29 de enero de 2014, rad. n. ${ }^{\circ} 25000-23-$ 26-000-1995-10714-01(33806); E. Gil Botero, sentencia del 09 de julio de 2014, rad. n. ${ }^{\circ}$ 70001-23-31-000-1998-00808-01(44333).

22 Consejo de Estado. Sala de lo Contencioso Administrativo. Sección Tercera. Subsección C. C. P. Enrique Gil Botero. Sentencia del 21 de noviembre de 2013. Rad. n. ${ }^{\circ}$ 05001-23-31-000-1998-0236801(29764).

23 Consejo de Estado. Sala de lo Contencioso Administrativo. Sección Tercera. Subsección C. C. P. Jaime Orlando Santofimio. 12 de febrero de 2014. Rad. n. ${ }^{\circ}$ 50001-23-31-000-2000-00001-01(26013).
También, ha reiterado que el control de convencionalidad es obligatorio y oficioso para todos los jueces:

Adicional a las normas procedimentales que rigen el trámite de los procedimientos contenciosos administrativos, el Despacho precisa que al momento de su interpretación y aplicación el funcionario judicial no sólo debe remitirse a ellas sino que en su razonamiento debe acudir a las normas constitucionales y de orden supraconstitucional, donde se enfatiza en la Convención Americana de Derechos Humanos y la doctrina desarrollada a partir de ella por la Corte Interamericana de Derechos Humanos.

Lo anterior en razón a que ya es un lugar común sostener que el Juez Administrativo no es un mero ejecutor formal de las normas legales sino que en razón al rol funcional que desempeña dentro del Estado Social de Derecho, es su obligación, antes que nada, ser garante de la corrección constitucional en la interpretación y aplicación de las normas legales, al igual que ejercer, ex oficio, el control de convencionalidad que se le impone en razón a la fuerza vinculante de los tratados de Derechos Humanos y su doctrina (CE, 24 sept. 2012, J. O. Santofimio).

En consecuencia, para el Consejo de Estado el control de convencionalidad no se limita a la contrastación objetiva de la norma interna con el parámetro convencional, sino que se extiende a condenar las prácticas y actos de cualquier naturaleza que puedan implicar una violación de las garantías comprendidas en el corpus iuris interamericano o los derechos reconocidos en los diferentes instrumentos internacionales. 
Adicionalmente, la corporación en mención ha tenido un importante desarrollo en cuanto a las medidas de reparación no pecuniarias, acogiendo el "principio de indemnidad" y la restitutio in integrum que también ha sido fundamental en el desarrollo jurisprudencial de la Corte IDH, lo que demuestra la penetración del derecho internacional de los derechos humanos en nuestra jurisprudencia.

Sin perjuicio de coincidencias de la jurisprudencia del Consejo de Estado con las características del control de convencionalidad desarrollado por la Corte IDH, aún se encuentran barreras por romper para ejercer este tipo de control, toda vez que no hay una aplicación directa de las normas del corpus iuris interamericano sino que se siguen integrando con el ordenamiento jurídico interno, a través de la figura del bloque de constitucionalidad, de forma coincidente con la posición de la Corte Constitucional: ${ }^{24}$

El control de convencionalidad es un principio de aplicación imperativa, que aunque aparentemente tiene una dimensión destructiva - dejar de lado el derecho interno- ello se supera al trascender a la dimensión integrativa que permite presentar una normativa que conjuga finalmente, un ordenamiento jurídico, como un todo (CE, 09 jul. 2013, E. Gil Botero).

Sobre este punto, resulta relevante recordar la providencia en la cual el Consejo de Estado estudió la prescripción de la acción de reparación directa, en el caso de una de las víctimas de lo

24 Ver, entre otras: Consejo de Estado. Sala de lo Contencioso Administrativo. Sección Tercera. Sentencia del 21 de noviembre de 2013. C. P. Enrique Gil Botero. Exp. n. ${ }^{\circ} 29.764$. ocurrido el 6 y 7 de noviembre de 1985 en la toma y retoma del Palacio de Justicia, donde concluyó que en este caso no podía aplicarse la prescripción establecida en el numeral $8^{\circ}$ del artículo 136 del Código Contencioso Administrativo para esta acción, debido a que se trataba de hechos que podían enmarcarse dentro de los considerados delitos de lesa humanidad por diferentes instancias y tratados internacionales, entre estos, el desarrollo jurisprudencial de la Corte IDH.

En este caso, el recurrente propuso la excepción de inconstitucionalidad de dicho artículo del Código Contencioso Administrativo, frente a lo cual el Consejo de Estado insistió en su posición de la integración normativa del derecho internacional de los derechos humanos y del derecho internacional humanitario con el ordenamiento jurídico interno, a pesar de reconocer la prevalencia de aquellos sobre este.

Precisamente, en esta sentencia se evidencia un avance jurisprudencial porque se hace un Ilamado a los jueces de lo contencioso administrativo para que, en ejercicio del control de convencionalidad, realicen la integración normativa del derecho internacional de los derechos humanos y del derecho internacional humanitario y apliquen sus disposiciones en los casos concretos "bien sea de manera directa (por haber sido firmados y ratificados los textos normativos), o por vía de la aplicación de los principios (mandatos imperativos) del ius cogens, de humanidad, así como sustentado en el criterio de universalidad" (CE, 17 oct. 2013, J. O. Santofimio, rad. n. ${ }^{\circ}$ 11001-03-26-000-2012-00078-00(45679)). 
No obstante, es importante resaltar que con el mismo razonamiento de la prevalencia del derecho internacional de los derechos humanos, el Consejo de Estado pudo dar un salto y aplicar la excepción por inconvencionalidad de esta norma, cuya omisión de un supuesto relacionado con la imprescriptibilidad de los hechos configurativos de delitos de lesa humanidad se encuentra fuera de lo establecido en el corpus iuris interamericano y puede implicar un hecho ilícito internacional.

Al contrario, el Consejo de Estado se inclinó por una posición más tímida de interpretación armónica de esta norma interna, y consideró que:

La norma cuestionada no entra en colisión, ni produce inconstitucionalidad alguna con las normas que tutelan el acceso a la administración de justicia (artículos 228-229 Constitución Política), ni cercena o restringe el derecho a la verdad. Lo anterior, tiene como sustento, precisamente, el efecto integrador con el que el Despacho ha venido construyendo la regla normativa según la cual en aquellos eventos en los que se demanda en ejercicio de la acción de reparación directa la responsabilidad del Estado por actos de lesa humanidad, no opera la caducidad dado el carácter imperativo que se deriva de la imprescriptibilidad de tales actos. Así mismo, se afirma que la integración normativa lejos de producir la negación, la excepción, o incluso la inconstitucionalidad reclamada del numeral $8^{\circ}$ del artículo 136 del Código Contencioso Administrativo, lo que permite es completar, colmar y definir la regla jurídica que opera para estos eventos (CE, 17 oct. 2013 , J. O. Santofimio, rad. n. ${ }^{\circ} 11001-03-$ 26-000-2012-00078-00(45679)).

\section{CONCLUSIONES}

La aplicación del control de convencionalidad es un paso muy importante en:

La construcción de un auténtico "diálogo jurisprudencial" -entre los jueces nacionales y los interamericanos-, [que] seguramente se convertirá en el nuevo referente jurisdiccional para la efectividad de los derechos humanos en el siglo XXI. Ahí descansa el porvenir: en un punto de convergencia en materia de derechos humanos para establecer un auténtico ius constitutionale commune en las Américas (McGregor, 2011, pág. 429).

En este sentido, como se ha demostrado, nuestra Constitución fue bastante progresista en la incorporación del derecho internacional, no solo para la interpretación de los derechos consagrados en ella, sino también como fuente normativa, lo que ha permitido que las altas cortes apliquen normas de derecho internacional integradas a las del derecho interno para resolver casos concretos. Derivado de esto, la Corte Constitucional construyó la figura jurídica del bloque de constitucionalidad, que ha servido para incorporar los instrumentos internacionales de derechos humanos que consagran derechos intangibles como parte del parámetro de control de constitucionalidad de las normas de inferior jerarquía.

Sin embargo, se observa que los jueces domésticos aún siguen siendo tímidos en la aplicación del control de convencionalidad como forma de control normativo y se han quedado con la integración normativa de los instrumentos de pro- 
tección de derechos humanos. Al respecto, el avance hacia esta dinámica es inevitable no solo por las obligaciones internacionales contraídas por los Estados y por la posición que ha ido consolidando la Corte IDH en esta materia, sino por el interés superior que supone la armonización de los ordenamientos jurídicos internos para velar por la protección efectiva de los derechos humanos, alcanzando cada vez estándares más altos, incluso que aquellos contemplados en la Constitución de cada país.

Precisamente por esto se considera necesario distinguir el control de convencionalidad como un análisis diferente al control de constitucionalidad, con el fin de replantear la supremacía de la Constitución y de otras normas internas, aun por encima del corpus iuris interamericano, lo cual cambiaría toda la jerarquía de las fuentes normativas en nuestro país.

Por tanto, si bien las consideraciones de la Corte IDH sobre el control difuso de convencionalidad no requieren un pronunciamiento adicional y expreso de ningún órgano del Estado para que se hagan exigibles a los jueces, sería importante que el tema fuera planteado desde la misma rama judicial al Congreso, para establecer exactamente qué procedimiento se va a seguir para efectos del control de convencionalidad, hasta dónde llega la competencia del juez en una posible declaratoria de inconvencionalidad y cuáles pueden ser las reglas de admisibilidad para el planteamiento de este análisis. Mientras este proceso de debate democrático sucede, puede ser adoptado un modelo a partir de la jurisprudencia progresista de la Corte Constitucional y del Consejo de Estado, en el que se contemple expresamente el análisis de convencionalidad de las normas, no incluido como consideraciones del control de constitucionalidad, sino como una aplicación directa del corpus iuris interamericano.

De esta manera, el Estado en su conjunto no solo a través de leyes, sino de sentencias, políticas públicas y demás manifestaciones del poder público, podrá darle un carácter trascendente, universal y eficaz a las obligaciones que contrajo con la protección de los derechos humanos.

\section{Referencias}

Ayala Corrao, C. M. (2008). Las modalidades de las sentencias de la Corte Interamericana y su ejecución. En E. Ferrer Mac-Gregor y A. Zaldivar Lelo de Larrea (Coords.), La ciencia del derecho procesal constitucional. Estudios en homenaje a Héctor-Fix Zamudio en sus cincuenta años como investigador del derecho (t. Ix). México: Universidad Nacional Autónoma de México. Instituto Mexicano de Derecho Procesal Constitucional. Marcial Pons

Cançado, A. (Octubre 16 de 2002). El derecho de acceso a la justicia internacional y las condiciones para su realización en el sistema interamericano de protección de los derechos humanos. Obtenido de jurídicas.unam: http://www.juridicas.unam.mx/publica/librev/rev/iidh/cont/37/pr/pr4.pdf

Castilla, K. (2011). El control de convencionalidad: un nuevo debate en México a partir de la 
sentencia del caso Radilla Pacheco. Obtenido de Instituto de Investigaciones Jurídicas unam: http://biblio.juridicas.unam.mx/estrev/pdf/ derint/cont/11/pim/pim20.pdf

Castilla, K. (Julio-diciembre 2014). Control de convencionalidad interamericano: una mera aplicación del derecho internacional. Revista Derecho del Estado, (33), pp. 149-172. Obtenido de Social Science Research Network: http://papers.ssrn.com/sol3/papers. cfm?abstract_id=2536450

Consejo de Estado. Sala de lo Contencioso Administrativo. Sección Tercera. Subsección A. Sentencia del 23 de febrero de 2012. Radicación n. ${ }^{0}$ 54001-23-31-000-1999-0038501(23027). (C. P. Hernán Andrade Rincón; febrero 23 de 2012).

Consejo de Estado. Sala de lo Contencioso Administrativo. Sección Tercera. Subsección C. Auto del 24 de septiembre de 2012. Exp. 50001-23-31-000-2011-00586-01 (44050). (C. P. Jaime Orlando Santofimio Gamboa; septiembre 24 de 2012).

Consejo de Estado. Sala de lo Contencioso Administrativo. Sección Tercera. Subsección C. Sentencia del 17 de octubre de 2013. Radicación n. ${ }^{\circ}$ 11001-03-26-000-2012-0007800(45679). (C. P. Jaime Orlando Santofimio Gamboa; octubre 17 de 2013).

Consejo de Estado. Sala de lo Contencioso Administrativo. Sección Tercera. Subsección C.
Sentencia del 21 de noviembre de 2013. Radicación n. ${ }^{\circ}$ 05001-23-31-000-1998-0236801(29764). (C. P. Enrique Gil Botero; noviembre 21 de 2013).

Consejo de Estado. Sala de lo Contencioso Administrativo. Sección Tercera. Subsección B. Sentencia del 06 de diciembre de 2013. Radicación n. ${ }^{\circ}$ 05001-23-31-000-2000-0338001(26669). (C. P. Ramiro de Jesús Pazos Guerrero; diciembre 6 de 2013).

Consejo de Estado. Sala de lo Contencioso Administrativo. Sección Tercera. Subsección A. Sentencia del 29 de enero de 2014. Radicación n. ${ }^{\circ}$ 25000-23-26-000-1995-1071401(33806). (C. P. Hernán Andrade Rincón; enero 29 de 2014).

Consejo de Estado. Sala de lo Contencioso Administrativo. Sección Tercera. Subsección C. Sentencia de febrero 12 de 2014. Radicación n. ${ }^{\circ}$ 50001-23-31-000-2000-0000101(26013). (C. P. Jaime Orlando Santofimio Gamboa; febrero 12 de 2014).

Consejo de Estado. Sala de lo Contencioso Administrativo. Sección Tercera. Subsección C. Sentencia del 09 de julio de 2014. Radicación n. ${ }^{\circ}$ 70001-23-31-000-1998-0080801(44333). (C. P. Enrique Gil Botero; julio 9 de 2014).

Corte Constitucional de Colombia. Sentencia T-1319 de 2001 (M. P.: Rodrigo Uprimny; diciembre 7 de 2001). 
Corte Constitucional de Colombia. Sentencia C-187 de 2006 (M. P.: Clara Inés Vargas Hernández; marzo 15 de 2006).

Corte Constitucional de Colombia. Sentencia C- 370 de 2006 (M. P.: Manuel José Cepeda Espinosa, Jaime Córdoba Triviño, Rodrigo Escobar Gil, Marco Gerardo Monroy Cabra, Álvaro Tafur Galvis, Clara Inés Vargas Hernández; mayo 18 de 2006).

Corte Constitucional. Sentencia C-936 de 2010

(M. P.: Luis Ernesto Vargas Silva; noviembre 23 de 2010).

Corte Constitucional de Colombia. Sentencia C-442 de 2011 (M. P.: Humberto A. Sierra Porto; mayo 25 de 2011).

Corte Interamericana de Derechos Humanos. Caso Almonacid Arellano y otros vs. Chile. Sentencia del 26 de septiembre de 2006. Excepciones Preliminares, Fondo, Reparaciones y Costas. Serie C n. ${ }^{\circ} 154$.

Corte Interamericana de Derechos Humanos. Caso Bámaca Velásquez vs. Guatemala. Sentencia de 25 de noviembre de 2000 . Fondo. Serie C n. ${ }^{\circ} 70$.

Corte Interamericana de Derechos Humanos. Caso Barrios Altos vs. Perú. Sentencia del 03 de septiembre de 2001. Interpretación de la sentencia de Fondo. (Art. 67 Convención Americana sobre Derechos Humanos). Serie C n. ${ }^{\circ} 83$.
Corte Interamericana de Derechos Humanos. Caso Caballero Delgado y Santana vs. Colombia. Sentencia del 29 de enero de 1997. Reparaciones. Serie $\mathrm{C} n{ }^{\circ} 17$. Voto disidente del juez Antonio A. Cançado Trindade.

Corte Interamericana de Derechos Humanos. Caso Cabrera García y Montiel Flores vs. México. Sentencia del 26 de noviembre de 2010. Excepción Preliminar, Fondo, Reparaciones y Costas. Serie C n. ${ }^{\circ} 220$.

Corte Interamericana de Derechos Humanos. Caso Caesar vs. Trinidad y Tobago. Sentencia 11 de marzo 2005. Fondo, Reparaciones y Costas. Serie C n. ${ }^{\circ} 123$.

Corte Interamericana de Derechos Humanos. Caso Comunidad indígena Yakye Axa vs. Paraguay. Sentencia 17 de junio de 2005. Fondo, Reparaciones y Costas. Serie C n. 125.

Corte Interamericana de Derechos Humanos. Caso Comunidad Moiwana vs. Suriname. Sentencia 15 de junio de 2005. Excepciones preliminares, Fondo, Reparaciones y Costas. Serie C n. ${ }^{\circ} 124$.

Corte Interamericana de Derechos Humanos. Caso del Penal Miguel Castro Castro vs. Perú. Sentencia de 25 de noviembre de 2006. Fondo, Reparaciones y Costas. Serie C n. 160.

Corte Interamericana de Derechos Humanos. Caso de la Masacre de Mapiripán vs. Colombia. Sentencia de 15 de septiembre de 2005. Fondo, Reparaciones y Costas. Serie C n. ${ }^{\circ}$ 134. 
Corte Interamericana de Derechos Humanos. Caso de la "Panel Blanca" (Paniagua Morales y otros) vs. Guatemala. Sentencia de 8 de marzo de 1998. Fondo. Serie C No. 37. Serie C n. ${ }^{\circ} 37$.

Corte Interamericana de Derechos Humanos. Caso de los Hermanos Gómez Paquiyauri vs. Perú. Sentencia de 8 de julio de 2004. Fondo, Reparaciones y Costas. Serie C n. 110.

Corte Interamericana de Derechos Humanos. Caso de los "Niños de la Calle" (Villagrán Morales y otros) vs. Guatemala. Sentencia de 11 de septiembre de 1997. Excepciones Preliminares. Serie $\mathrm{C}$. ${ }^{\circ} 32$.

Corte Interamericana de Derechos Humanos. Caso Godínez Cruz vs. Honduras. Sentencia de 20 de enero de 1989. Fondo. Serie C n. ${ }^{\circ}$ 5.

Corte Interamericana de Derechos Humanos. Caso Gómez Palomino vs. Perú. Sentencia de 22 de noviembre de 2005. Fondo, Reparaciones y Costas. Serie C n. 136.

Corte Interamericana de Derechos Humanos. Caso González y otras ("Campo Algodonero") vs. México. Sentencia de 16 de noviembre de 2009. Excepción Preliminar, Fondo, Reparaciones y Costas. Serie C n. 205.

Corte Interamericana de Derechos Humanos. Caso Heliodoro Portugal vs. Panamá. Sentencia de 12 de agosto de 2008. Excepciones Preliminares, Fondo, Reparaciones y Costas. Serie C n. ${ }^{\circ} 186$.
Corte Interamericana de Derechos Humanos. Caso La Cantuta vs. Perú. Sentencia del 29 de noviembre de 2006. Fondo, Reparaciones y Costas. Serie C n. ${ }^{\circ} 162$.

Corte Interamericana de Derechos Humanos. Caso "La Última Tentación de Cristo" (Olmedo Bustos y otros) vs. Chile. Sentencia de 5 de febrero de 2001. Fondo, Reparaciones y Costas. Serie C n. ${ }^{\circ} 73$.

Corte Interamericana de Derechos Humanos. Caso Lori Berenson Mejía vs. Perú. Sentencia de 25 de noviembre de 2004. Fondo, Reparaciones y Costas. Serie C n. 119.

Corte Interamericana de Derechos Humanos. Caso Myrna Mack Chang. Sentencia de 25 de noviembre de 2003. Fondo, Reparaciones y Costas. Serie C No. 73.

Corte Interamericana de Derechos Humanos. Caso Neira Alegría y otros. Sentencia de 19 de enero de 1995. Serie C, n. ${ }^{\circ} 20$.

Corte Interamericana de Derechos Humanos. Caso Perozo y otros vs. Venezuela. Sentencia del 28 de enero de 2009. Excepciones Preliminares, Fondo, Reparaciones y Costas. Serie C n. ${ }^{\circ} 195$.

Corte Interamericana de Derechos Humanos. Caso Radilla-Pacheco vs. México. Sentencia del 23 de noviembre de 2009. Excepciones Preliminares, Fondo, Reparaciones y Costas. Serie C n. 209. 
Corte Interamericana de Derechos Humanos. Caso Raxcacó Reyes vs. Guatemala. Sentencia de 15 de septiembre de 2005 . Serie $\mathrm{C}$. ${ }^{\circ}$ 133.

Corte Interamericana de Derechos Humanos. Caso Trabajadores Cesados del Congreso (Aguado Alfaro y otros) vs. Perú. Sentencia del 24 de noviembre de 2006. Excepciones Preliminares, Fondo, Reparaciones y Costas. Serie C n. ${ }^{\circ} 158$.

Corte Interamericana de Derechos Humanos. Caso Trujillo Oroza vs. Bolivia. Sentencia de 26 de enero de 2000. Fondo. Serie C n. 64.

Corte Interamericana de Derechos Humanos. Caso Velásquez Rodríguez vs. Honduras. Sentencia del 29 de julio de 1988 . Serie C n. 4.

Corte Interamericana de Derechos Humanos. Caso Villagrán Morales y otros (caso de los "Niños de la calle"). Sentencia del 19 de noviembre de 1999 , serie $C$, n. $^{\circ} 63$

Corte Interamericana de Derechos Humanos. Caso Ximenes Lopes vs. Brazil. Excepción Preliminar. Sentencia del 30 de noviembre de 2005 y también Fondo, Reparaciones y Costas. Serie C n. ${ }^{\circ}$ 149. Sentencia del 04 de julio de 2006.

Corte Interamericana de Derechos Humanos. Caso Torres Millacura y otros vs. Argentina. (2011). Fondo, Reparaciones y Costas. Serie $\mathrm{C}$ n. 229.
Corte Interamericana de Derechos Humanos. Caso Boyce y otros vs. Barbados. Excepción Preliminar, Fondo, Reparaciones y Costas. Sentencia de 20 de noviembre de 2007. Serie $\mathrm{C}$. ${ }^{\circ} 169$.

Corte Interamericana de Derechos Humanos. Opinión Consultiva OC-1/82, 24 de septiembre 1982. "Otros tratados" objeto de la función consultiva de la Corte (art. 64 Convención Americana sobre Derechos Humanos). Serie A n. ${ }^{\circ} 1$.

Corte Interamericana de Derechos Humanos. Opinión Consultiva OC-3/83 del 08 de septiembre de 1983. Restricciones a la Pena de Muerte (arts. 4.2 y 4.4 Convención Americana sobre Derechos Humanos). Serie A n. ${ }^{\circ} 3$.

Corte Interamericana de Derechos Humanos. Opinión Consultiva OC-8/87 del 30 de enero de 1987. El hábeas corpus bajo suspensión de garantías (arts. 27.2, 25.1 y 7.6 Convención Americana sobre Derechos Humanos). Serie A n. ${ }^{\circ} 8$.

Corte Interamericana de Derechos Humanos. Opinión Consultiva OC-13/93 del 16 de julio de 1993. Ciertas atribuciones de la comisión interamericana de derechos humanos (arts. 41, 42, 44, 46, 47, 50 y 51 de la Convención Americana sobre Derechos Humanos).

Corte Interamericana de Derechos Humanos. Opinión Consultiva OC-14/94 del 9 de diciembre de 1994. Responsabilidad Internacional por Expedición y Aplicación de Leyes Violato- 
rias de la Convención (arts. 1 y 2 Convención Americana Sobre Derechos Humanos). Serie A n. ${ }^{\circ} 14$.

Del Toro, M. (Enero, 2005). La apertura constitucional al derecho internacional de los derechos humanos en la era de la mundialización y sus consecuencias en la práctica judicial. Boletín Mexicano de Derecho Comparado, (112). Obtenido de Biblioteca Jurídica Virtual: http://www.juridicas.unam.mx/publica/rev/ boletin/cont/112/art/art9.htm

Fajardo Morales, Z. (s.f.). El control difuso de convencionalidad en México: elementos dogmáticos para una aplicación práctica [en proceso de edición e impresión]. Obtenido de sitios.scjn: http://www.sitios.scjn.gob.mx/ reformasconstitucionales/sites/default/files/material_lectura/Fajardo\%20Control\%20 Convencionalidad.pdf

Gómez-Robledo Verduzco, A. (2000). Derechos humanos en el Sistema Interamericano. México: Porrúa-unam.

Hitters, J. C. (2008). ¿Son vinculantes los pronunciamientos de la Comisión y de la Corte Interamericana de Derechos Humanos? (control de constitucionalidad y convencionalidad). Revista Iberoamericana de Derecho Procesal Constitucional, (10), 131-155.

Ledesma, H. (2010). El agotamiento de los recursos internos en el Sistema Interamericano de Protección de los Derechos Humanos. Obtenido de iidh.ed: http://www.iidh.ed.cr/mul-
tic/UserFiles/Biblioteca/IIDH/2_2010/XXVCurso_Inter_en_Derechos_Humanos_Discursos_ponencias/17.\%20HFaundez_doc.pdf

Mac-Gregor Ferrer, E. (Mayo-Agosto, 2011). Reflexiones sobre el control difuso de convencionalidad. A la luz del caso Cabrera García y Montiel Flores vs. México. Boletín Mexicano de Derecho Comparado, XLIV(131), 917-967.

Mondragón Reyes, S. (2010). La jurisprudencia de la Corte Interamericana de Derechos Humanos. Revista del Instituto de la Judicatura Federal, (29). Obtenido de ijf.cjf: http://www. ijf.cjf.gob.mx/publicaciones/revista/29/Salvador\%20Mondrag\%C3\%B3n\%20Reyes.pdf

Nogueira, H. (2011). El uso de las comunicaciones transjudiciales por parte de las jurisdicciones constitucionales en el derecho comparado y chileno. Estudios Constitucionales, 9(2), 17-76.

Nogueira, H. (2012). Los desafíos del control de convencionalidad para los tribunales nacionales, en especial para los tribunales constitucionales. En Reflexiones en torno al derecho procesal constitucional: III Congreso Colombiano de Derecho Procesal Constitucional. Bogotá: Universidad El Bosque, Facultad de Ciencias Jurídicas y Políticas: Centro Colombiano de Derecho Procesal Constitucional.

Ortiz Ahlf, L. (Abril, 2005). Armonización legislativa interna de las normas internacionales en materia de derechos humanos (págs. 287302). En Memorias del Seminario: La armo- 
nización de los tratados internacionales de derechos humanos en México. México: Programa de Cooperación sobre Derechos Humanos/Comisión Europea.

Rodríguez Rescia, V. (1997). La ejecución de sentencias de la Corte Interamericana de Derechos Humanos. Obtenido de corteidh: http://www.corteidh.or.cr/tablas/12835.pdf

Rodríguez Rescia, V. (1998). La ejecución de sentencias de la Corte. En: F. Cox, J. Méndez e Inter-American Institute of Human Rights, El futuro del sistema interamericano de protección de derechos humanos. San José, Costa Rica: Instituto Interamericano de Derechos Humanos.

Sagüés, N. (2008). Censura judicial y derecho de réplica. Buenos Aires: Ed Astrea.
Sagüés, N. (2010). Obligaciones internacionales y control de convencionalidad. Estudios Constitucionales, 8(1), 117-136. Obtenido de scielo: http://www.scielo.cl/scielo.php?pid=S071852002010000100005\&script=sci_arttext.

Verbic, F. (2012). Control de convencionalidad en el sistema interamericano de protección de derechos humanos: principales características y algunos apuntes sobre su aplicación en el ordenamiento jurídico argentino. Concurso “Niceto Alcalá Zamora y Castillo". XXIII Jornadas Iberoamericanas de Derecho Procesal y I Conferencia Internacional sobre Procesos Colectivos/Class Actions, celebrada en la ciudad de Buenos Aires los días 6 al 9 de junio de 2012. 